\title{
Microbial Fuel Cells: An Alternate Approach for Bioelectricity Generation and Waste Management
}

\author{
Chennappa Gurikar* (D) H.B. Vandana, B.P. Netravati, B.P. Chaitra Kumari, \\ N.A. Nanje Gowda (D), K.N. Hanumantharaju and Lokesh AC \\ Department of Food Technology, Ramaiah University of Applied Sciences, Bangalore - 560 054, Karnataka, \\ India.
}

\begin{abstract}
Microbial Fuel Cells (MFCs) are the device that involves bacteria and organic matter, to generate electrical current via bacterial metabolism from a wide range of organic and inorganic substrates. MFCs are novel bioreactors, that convert chemical energy into electrochemical energy through bio-catalysis of various wastes (agriculture, food, households, food processing industries) using microorganisms. MFC is a promising approach that offers direct, clean, green energy generation, ease of waste recyclability, and by-product utilization of different sources. In recent, MFCs research advances related to electrode development and utilization of suitable different rural and urban wastes is a significant interest in the MFC application. Hence in a large-scale application, the MFC concept is one of the effective technologies for the management of different wastes and is simultaneously used for electricity generation to cater to the energy demand in rural or remote areas that are not linked to the electric grid. MFCs help reduce the global energy crisis and reduce the pressure on non-renewable energy resources.

Keywords: Fuel Cells, Bioelectricity, Agriculture wastes, Eco-friendly
\end{abstract}

\footnotetext{
*Correspondence: chinnagurikar@gmail.com
}

(Received: September 02, 2021; accepted: October 25, 2021)

Citation: Gurikar C, Vandana HB, Netravati BP, et al. Microbial Fuel Cells: An Alternate Approach for Bioelectricity Generation and Waste Management. J Pure App/ Microbiol. 2021;15(4):1833-1845. doi: 10.22207/JPAM.15.4.74

(C) The Author(s) 2021. Open Access. This article is distributed under the terms of the Creative Commons Attribution 4.0 International License which permits unrestricted use, sharing, distribution, and reproduction in any medium, provided you give appropriate credit to the original author(s) and the source, provide a link to the Creative Commons license, and indicate if changes were made. 


\section{INTRODUCTION}

Globally the human population is increasing enormously and parallelly industries are being established to maintain the growth and developments. Due to human and industrial activities, the energy is alarmingly strong, putting extreme strain on non-renewable energy supplies. Thermal power plants have been constructed and coal is the major source for energy production. As a result of this, the non-renewable fossil fuel sources are rapidly depleted causing an environmental imbalance. Additionally, the combustion of fossil fuels releases a huge amount of $\mathrm{CO}_{2}$, which is a primary greenhouse gas and has created alarming consequences on the environment. ${ }^{1}$ Many energies production concepts that have been studied and applied on large scale are solar energy, wind energy, hydraulic energy, etc., but all are limited to some extent application-wise.

Globally, a million tonnes of waste (agriculture, industry, and domestic) is being burnt, and sometimes it is buried in the lands to avoid a negative impact on the ecosystem. The majority of the waste is burnt in the land itself and leads to environmental pollution. There is a necessity for an alternate approach of nonrenewable energy sources and waste management side by side, which is an environmentally sustainable approach. One such promising approach is the MFCs, which offer direct, clean, and green energy generation by using a combination of different types of wastes and microorganisms. ${ }^{2}$ In the MFC system, microorganisms utilize the nutrients from the waste and release a part of the energy in the form of electricity. The MFC concept, production of electricity using microbes was first proposed in 1911. This concept laid the foundation for establishing research on the development of MFC's in the $20^{\text {th }}$ century. ${ }^{3}$ Lately, renewable energy is necessary for domestic waste management and triggered research interests in emerging MFC technology to cater to human needs for the sustainable development energy sector. ${ }^{4}$

The MFC mechanism involves the catalytic reaction of microorganisms with the nutrient source within a closed system to transform chemical energy to electrical energy. ${ }^{5}$ Microbes are responsible for metabolizing the organic compounds from the wastes, metabolism of these organic compounds generates electrons and protons. ${ }^{1,6}$ The adaptability of broad-range bacterial genera with different kinds of wastes (organic matter) makes the MFC system a commendable technology to produce electricity. ${ }^{7}$ A different group of microflora, most of them are bacteria that have been claimed to generate electricity. Different classes of bacterial genera viz., acidobacteria, proteobacteria, and firmicutes are known to produce electric current, and yeast, microalgae, and fungi have also been used to facilitate the electrode in MFCs. ${ }^{8,7}$

The technical terms used for the microbes applied for MFCs are Exoelectrogens, electrogenic microorganisms, electrochemically active bacteria, anodophiles, anode-respiring bacteria, and electrogens, which are responsible for transferring electrons to the anode. ${ }^{7}$ These microbes can transfer electrons to an anode chamber without any mediator or compounds. All microbial sources cannot break down mediators or compounds viz., neutral red, thionine, meldola's blue, methylene blue, Fe (III) EDTA due to their toxicity on microbe metabolism. ${ }^{9}$

Different organic substrates can be employed as a probable energy source for microbes and may help in the development of an effective and efficient MFC system. An initial step of hydrolysis and fermentation is essential to break complex macromolecule substances into a simpler form and then transform them into freely decomposable substrates, later which is biodegraded another anode respiring bacteria. ${ }^{10}$ MFC-based technologies have been developed for wastewater treatment, microbial electrolysis cells, sediment MFC and bioremediation processes ${ }^{11}$ and among them, wastewater treatment is the most used strategy. ${ }^{11,12,6,13}$

\section{MFC design and development}

MFCs are evolving as a versatile renewable energy source is because this eco-friendly technology has a wide range of applications. Any biodegradable organic matter (simple and complex molecules) of different agro and food industry wastes and wastes produced from it etc., can be used in MFC to produce electricity. It is an ideal technology for sustainable bioelectricity generation from different biomass because of the flexibility of microorganisms to use a range of wastes as fuels for activities. ${ }^{7,6,14}$ The MFCs are the bio-electrochemical devices where the 
structural constructions vary significantly, from single and double-chamber configurations and in the presence or the absence of proton exchange membrane (PEM).

PEMs are selectively permeable to protons and have other favorable properties such as high cation conductivity, low internal resistance, and the potential to remain active for long periods without disturbing the MFC. So, PEM is considered the most frequently used membrane separator in double-chambered MFCs. ${ }^{15}$ These biochemical devices mainly consist of a chamber(s), electrodes, and substrates depending upon various aspects of construction required for a range of utilities. The MFC containing cathodic and anodic chambers that are separated by a PEM or a salt bridge, in which anodic chamber is kept in anaerobic condition and the cathodic chamber can hold either aerobic or anaerobic is termed as dual-chamber MFC (Fig 1.). On the other hand, single-chambered MFCs hold both cathode and anode in a single chamber. ${ }^{16}$

This technology associates microbial metabolism with electrochemical reactions and helps simultaneously to generate electric power and for the management of waste accumulation. Electro-active bacteria have molecular machinery that allows them to transmit electrons to an electron acceptor without any additional intervention and are popularly known as exoelectrogens. ${ }^{16}$ They are used as biocatalysts in the anode chamber to oxidize the organic matter (waste substrate) and convert chemical energy provided by oxidation of organic/inorganic compounds into ATP by sequential reactions. The microorganisms which are involved in the electricity generation using organic wastes are called as powerhouse of the MFCs. ${ }^{8}$

The microbial metabolism of organic compounds develops bio-potential that results in the generation of electrons and protons. ${ }^{15}$ In the MFC system, electrons are transferred to the anodic surface, electrons and protons react in the cathode chamber with a simultaneous decrease of oxygen to water levels. ${ }^{17}$ Exoelectrogenic bacteria oxidize organic matter in the anode chamber, due to oxidation reaction, which results in a reduction of an electron acceptor and increases redox potential in the cathode chamber. The disparity in redox potentials causes electrons to flow from anode to cathode, which results in electricity generation. ${ }^{16,18}$

\section{Single chamber MFC}

A single chamber MFC system offers modest configuration and eliminates the requirement of a cathode chamber and the PEM. ${ }^{18,19}$ Park and Zeikus developed first a single chamber MFC as a demo working model. This device consisted of a window-mounted cathode

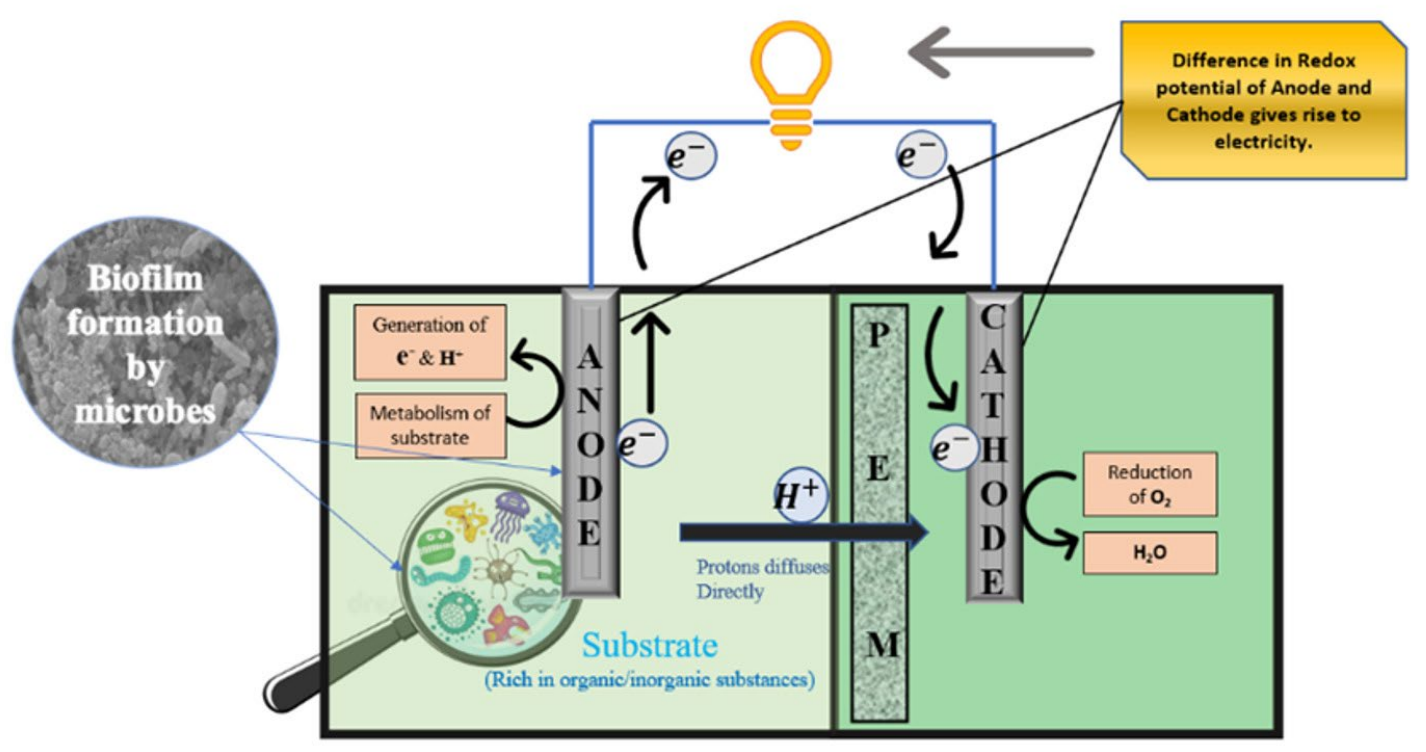

Fig. 1. Schematic diagram of working principle of microbial fuel cells. 
with an internal proton-permeable porcelain sheet, a rubber-stopped container with an anode at the center, and sewage sludge as biocatalyst that produced the maximum power density. ${ }^{15}$ The effect of temperature on single chamber MFC was studied by Cheng et $\mathrm{al}^{20}$ and observed that for repeatable power cycles and improved performance, a temperature range of $4-30^{\circ} \mathrm{C}$ was essential in terms of set-up time. It is concluded that, for MFC operation, temperature plays a major role in the generation of electricity and metabolism of organic substrates ${ }^{20,21}$ attempted to improve the voltage output of single-chambered MFC using microfiltration membranes (MFM). It was observed that there was a $29 \%$ higher voltage obtained in the MFCs with MFM compared to the MFC containing PEM as a separator. The comparative results between the singlechambered MFC with PEM and MFM proved that the MFM offers a substantial increase in power output, coulombic efficiency, and internal resistance. ${ }^{21}$

\section{Double chamber MFC}

The double-chambered MFCs are characteristically utilized with a given medium such as acetate or glucose-rich substrates. The structural designs of double-chambered MFC vary in shapes ranging from typical rectangular to cylindrical, and flat plate MFCs. ${ }^{15}$ The doublechambered MFC build up in a classic " $\mathrm{H}$ " shape consists of an anode and the cathode chamber coupled by a cylindrical tube with a PEM at the center. PEM facilitates proton transition from anode to cathode simultaneously blocking the diffusion of oxygen into the anode. An anode (anaerobic) chamber consists of an electrode (carbon felt, carbon brush) and is fed with the substrate, while water or phosphate buffer is used in the cathodic chamber as an electrolyte ${ }^{15}$.

\section{Electrodes}

Designing and application of electrodes is a great task in the development of scalable MFC technology. The electron transfer from an anode to a cathode is brought about by the conducting material known as an electrode. ${ }^{22}$ An ideal electrode used in the construction of MFCs should possess the qualities such as good electrical conductivity, have more surface area, less external resistance, non-corrosive, biocompatible, chemical, and mechanical stability. ${ }^{23}$ The anode materials such as carbon cloth, rods, glassy carbon, carbon felt, granules, carbon paper, carbon foam, graphite plates, platinum, polypyrrole nanotube, and, platinum black is used in the construction of MFCs. ${ }^{8,24}$ Cathode materials are made of Pt black, graphite, carbon felt, glassy carbon, carbon paper, carbon form, Pt, carbon cloth, and reticulated vitreous carbon. ${ }^{25,23,22,15}$ The key advancements in anode electrodes are the enhancement of biofilm formation of electro-genic bacteria on the electrode surface.

The electrode material is the major and important component for designing of MFC that affects both the performance and the cost. The electrodes are the conducting material that transfers electrons from anode to cathode causing the useful flow of electrons. The efficient electrode material must have several important properties as discussed below.

\section{Surface area and porosity}

In MFCs, the surface area of the electrodes has a significant effect on power production and its output. Since electrode resistance is directly proportional to ohmic losses, a larger electrode surface area provides more reactions sites by increasing the electrode kinetics in the MFC system. For biofilm formation, more electrode surface is suitable for designing of MFC, and more the surface area more will be the bacterial accumulation.

\section{Electrical conductivity}

Electrons emitted by microbes by the formation of biofilm would proceed through an external circuit after passing through the anode. The electrode material with higher electrical conductivity has less resistance against the flow of electrons.

\section{Stability and durability}

The surface roughness of the electrode material might increase the durability and as well as cause fouling which decreases the efficiency of MFC. Electrodes material used for MFC should be stable and durable in alkaline and acidic conditions. An ideal electrode material should be cost-effective and must have favorable electrochemical properties (electron transfer), mechanical stability in conjunction with a large surface area, and offers a high current density. ${ }^{15}$

The anode material in MFCs not only serves as a conductor but also works as a support 
for bacterial biofilm formation, so it must be well-matched with the bacteria. The electrode materials area and roughness play an important role in the generation of electricity. ${ }^{24} \mathrm{~A}$ larger surface area with the lowest rough surface supports the bacterial biofilm formation on the electrode surfaces. Among many electrodes, nanomaterials-based carbon materials possess many advantageous properties (large surface area, enhanced electron transfer, and adsorption of molecules) make them perfect electrode materials for MFCs. Electrode modifications with nanomaterials such as gold nanoparticles and iron oxide nanoparticles or pretreatment methods such as sonication and autoclave sterilization have shown promising results in enhancing MFC performance for electricity generation and wastewater treatment. ${ }^{16,26}$ Among several methods made to increase the electric output in MFCs, anode surface modification with nanomaterials and bacterial gene modification are the most prevalent approaches. ${ }^{16}$

\section{Carbon-based electrodes}

Carbon is one of the most preferred and effective electrode materials since it is available in various forms of structure, shapes, and surface area which is a major requirement for designing of MFCs. Because of their high electrical conductivity, specific surface area, biocompatibility, chemical stability, and low cost, numerous studies have been performed to scale up power output using various carbon-based materials such as carbon fiber, carbon paper, carbon felt, and carbon nanotube-based composites. ${ }^{8,26}$

\section{Carbon cloth}

Carbon cloth has been one of the scientifically preferred electrode materials due to its useful properties like commercial availability, conductivity, stability, and relatively cheaper cost compared to other carbon-based electrode materials. Carbon cloth is made up of long carbon fibers that are formed by the thermal decomposition of acrylic. Individual fibers are then bound together to form a bundle, which is then woven together to make carbon cloth. $8,25,26,15$

\section{Carbon felt}

Carbon felt is a mat-like structure utilized as an electrode material along with electrodeposition with different materials to increase the efficiency of carbon felt. Various research has been performed on the cathodic electrodeposition to decorate the carbon felt surface with the $\mathrm{RuO}_{2}$ films composed of nanoparticles. It was observed that the $\mathrm{RuO}_{2}$ coated carbon felt anode exhibited substantially better power efficiency than the bare anode. $8,25,15$

\section{Graphite}

An exceptional electrochemical property along with bio-compatibility of graphite has been determined using scanning electron microscopy (SEM). It is also observed that an abundance of a monoculture biofilm (E. coli) adheres to a graphite

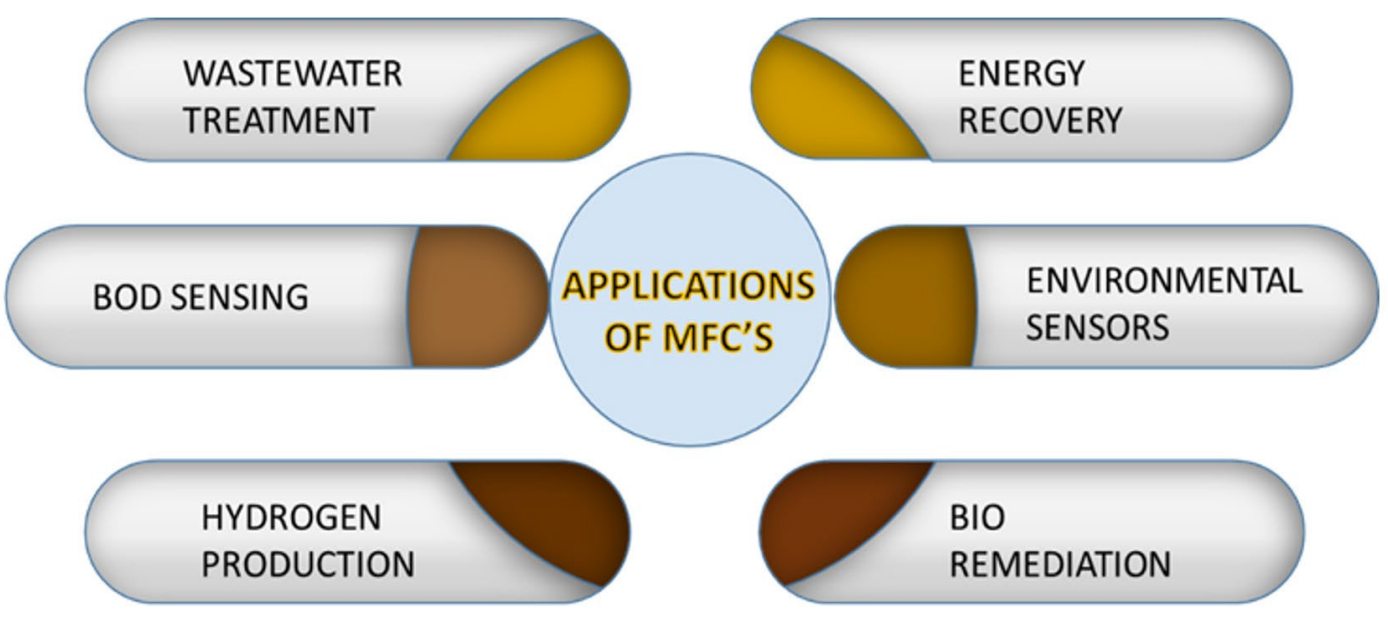

Fig. 2. Applications of Microbial Fuel Cells. 
electrode surface. Graphite felt electrodes compared to graphite rods alone have a threefold higher current generation. ${ }^{15}$

\section{Mediators}

In general, mediators are the chemical constituents used to enhance the performance of MFCs. Microbial fuel cells are of two types one is with and another one is without a mediator. In certain studies, the addition of mediators such as potassium ferry cyanide, neutral red, anthraquinone, thionine, disulfonic acid, azure, and cobalt sepulchrate are used for enhancing the performance of the MFC system. In these cases, microorganisms partly oxidize organic substrates and transfer a portion of these electrons to electrodes. The selection of mediators should consider turnover rate in the relation to the electrode. The mediator which promotes a high turnover of electrons rate should be selected for the designing of MFCs. ${ }^{27}$ The mediators are non-toxic to the microorganisms and are stable in both reduced and oxidized form and also are not biologically degradable. The electrons from microorganisms are squeezed out during metabolism by the mediators and enhance the electron generation from microorganisms to the electrode in the anode chamber. ${ }^{28}$ The surface area of the electrodes used determines the efficiency of the MFC without a mediator. Mediatorless microbial fuel cells normally use special microorganisms that can release electrons to the anode depending on the quantity, characteristics of the substrate, and inoculum available in the anode chamber. ${ }^{28,29}$

\section{Substrates used in MFC}

The substrate is a critical component required for any natural cycle as it fills in as a supplement or nutrient source and also a basic factor for the evolution of organisms. In MFCs, a substrate is viewed as one of the most significant organic variables, which influences power generation. ${ }^{30} \mathrm{~A}$ wide variety of substrates containing a high amount of carbohydrates are used, which could be either a simple compound or complex mixtures for electricity generation. The simple organic substrates containing acids such as malate, acetate, butyrate, succinate, propionate, alcohols (ethanol), and inorganic compounds (sulfate) are widely used for the development of MFCs. Similarly, complex substrates i.e., starch, cellulose, molasses, chitin starch and wastewaters coming from the meat packaging industry, swine farms, waste from food industries also used mainly as substrates as basic sources for MFCs (Fig. 2.). These organic sources have been shown to have a substantial impact on MFC's power density and output. $^{1}$

\section{Brewery wastewater}

Among various substrates, brewery waste is a good primary choice, as a substrate for designing of MFCs. Brewery waste is an ideal substrate because of its low ammonium nitrogen concentration and excessive carbohydrate content. This wastewater obtained from breweries and it is a good source is mainly due to its low strength. The concentration of brewery wastewater varies at the range of 3000-5000 $\mathrm{mg}$ of COD/L which has a concentration of around ten times that of domestic wastewater. In addition, it is most suitable for electricity generation in MFCs due to its organic content and free from high concentrations of inhibitory substances such as ammonia ${ }^{31,32}$ developed a polarization curve-based MFC model and found that the loss of kinetic reaction and mass transport are the most significant factors influencing the MFC output with brewery wastewater (Table 1). Hence, the use of a rough electrode to create further reaction sites and by increasing the quantity of brewery wastewater and the reaction temperature can prevent electricity loss. ${ }^{32}$

\section{Meat industry waste as substrate}

Meat processing wastewaters contain the highest amount of biochemical oxygen demand (BOD) and chemical oxygen demand (COD), making traditional aerobic treatment approaches prohibitively costly. As a result, treating these wastewaters with a technology that produces a valuable commodity, such as electricity, may have a significant economic advantage. ${ }^{33}$ The investigation of the protein-rich meat packaging wastewater was carried out by constructing the microbial fuel cells (single-chamber) using two electrodes placed on opposite sides which is 3 $\mathrm{cm}$ in diameter. The cathode was carbon paper with a $0.35 \mathrm{mg}$ platinum $/ \mathrm{cm}^{2}$ (wet proof) on one side and the anode was carbon paper (non-wet proof). The wastewater was diluted to $1: 4$ with ultrapure water to limit the time required for the completion of the batch cycle (Table 1). At dilutions 

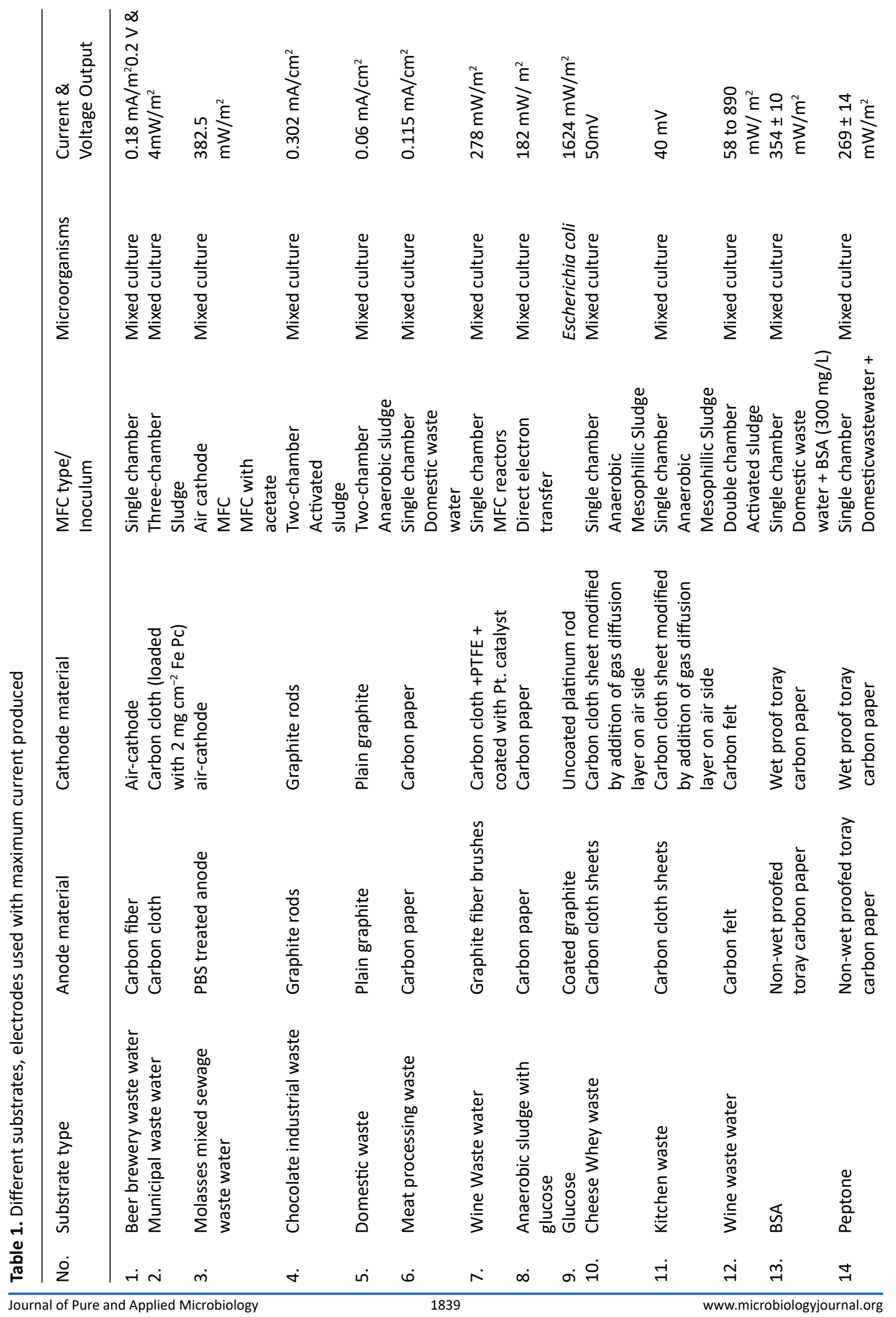


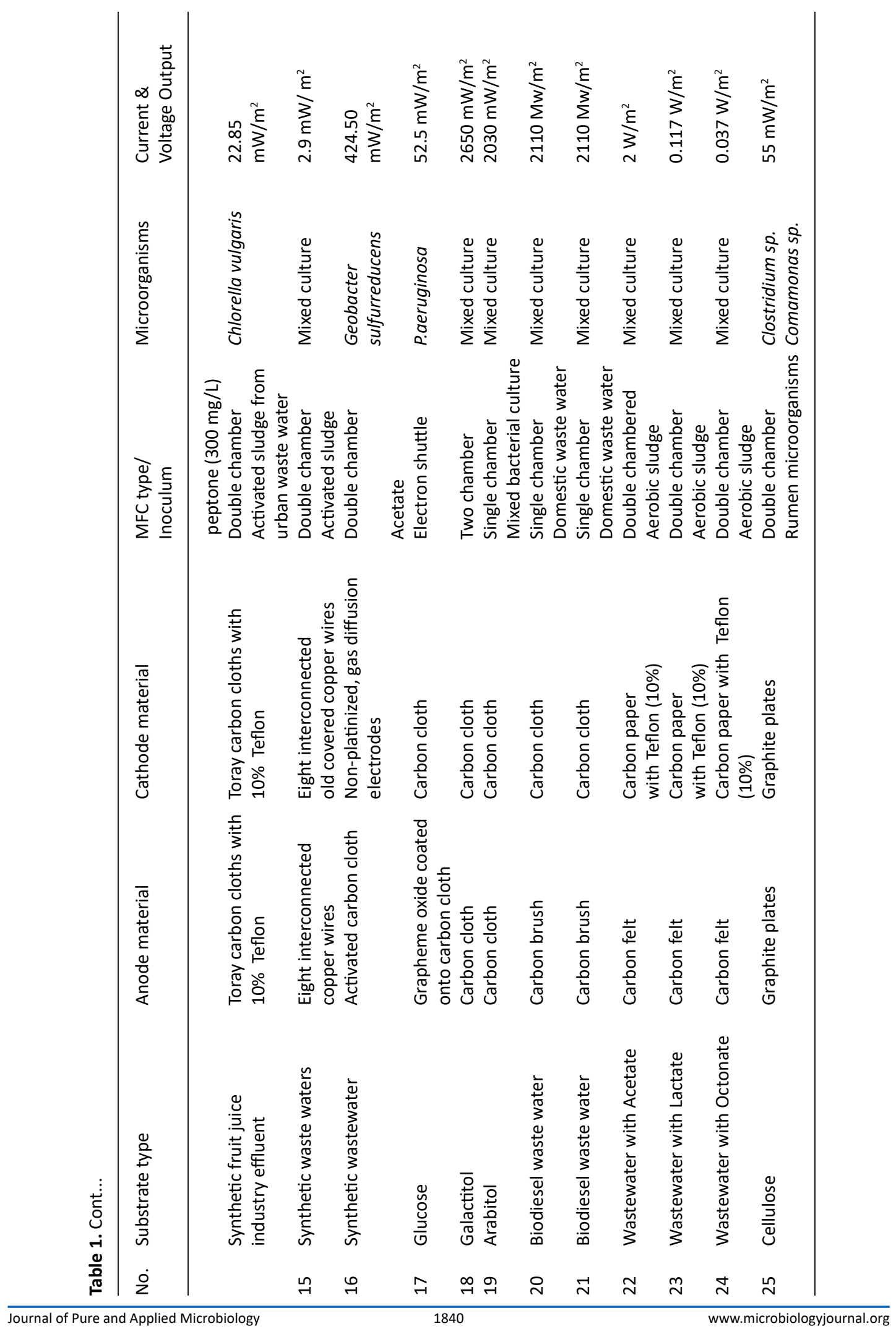


of $1: 2(218 \pm 2.2 \mathrm{mV})$ and $1: 4(217.3 \pm 1.5 \mathrm{mV})$, the overall voltage appeared to be similar, and power was increased by $33 \%$ by the addition of a mediator $(300 \mathrm{mg} / \mathrm{L} \mathrm{NaCl})$ to increase the solution conductivity. 33

\section{Agro-industrial Wastes}

Agricultural practices may accumulate a large number of wastes, which can be used for biofuels and animal fodder as well. In general, agro-food processing waste contains a large number of organic materials containing a varied range of $B O D, C O D$, and suspended solids. The wastes from processing streams require treatment to prevent water pollution due to the presence of pollutants in high concentrations. ${ }^{34,35}$ The power generation and efficacy of waste utilization by few agricultural by-products are used as a substrate for MFCs and a very important substrate to produce the energy (Table 1).

\section{Palm oil industry wastewater}

The palm oil agro-industry produces residual biomass is used in many emerging technologies such as synthesis of Palm oil mill effluent (POME) and palm oil mill bio-refineries, which seems to be most useful in the short term based on economic applications. ${ }^{36} \mathrm{~A}$ double chamber microbial fuel cell was designed using Nafion 117 (separate the chambers) membrane attached between the two electrodes chambers (anodic and cathodic). Polyacrylonitrile carbon felt (PACF) is used as an electrode for a dual MFC chamber. The anode chamber was inoculated with controlled inoculum $(\mathrm{Cl})$ collected from anaerobic sludge and filled with $450 \mathrm{~mL}$ of effluent collected from the palm oil industry effluent outlet (Table 1). The cathode chamber was filled with $450 \mathrm{~mL}$ potassium permanganate solution, which was retained at a steady concentration during the entire process of the MFC system. It was observed that the power density was twice when MFC was operated with the combination of $\mathrm{Cl}$ and PACF, as compared to MFC's usual sludge under anaerobic conditions. ${ }^{37}$

\section{Molasses Wastewater}

Molasses wastewater is a by-product of the sugar manufacturing process and absorbs high amounts of organic compounds such as protein, pectin, sugar, vitamins, amino acids and expends a large volume of dissolved oxygen (DO). The molasses wastewater is a dark brown hue with a
COD value of $65,000-130,000 \mathrm{mg} / \mathrm{L}$ and a BOD of $30,000-96,000 \mathrm{mg} / \mathrm{L}$. As a result, direct dumping of molasses wastewater can have negative consequences on aquatic living beings. Since the molasses wastewater serves as a source of glucose, this can rich energy source for microbial-based decomposition. The MFC was seen effective in treating actual molasses wastewater and also generating electricity. $38,39,40$

A dual-chambered MFC was fabricated and designed with molasses wastewater as the electron acceptor and outcomes have documented that it also supports stable electricity generation (Table 1). The highest electricity output (voltage $514.5 \mathrm{mV})$ and power density $\left(65.82 \mathrm{~mW} / \mathrm{m}^{2}\right)$ have been recorded in using an external resistance $(1,000 \Omega)$ and the chemical oxygen demand removal rate was $81.22 \%{ }^{39}$

\section{Cassava wastewater}

Wastewater from cassava mill is usually rich in starch and carbohydrate with maximum levels of BOD, TS, COD, and limited levels of ammonium nitrogen concentrations with high cyanide content $(3.5 \mathrm{mg} / \mathrm{L})$ and acidity $(\mathrm{pH} 4.5 \pm$ 5.5). ${ }^{34}$ These findings promote the use of cassava biomass in MFCs as a supplementary energy source, especially in cassava-producing countries facing severe energy crises. ${ }^{41}$ In another study, MFC was designed with plexiglass consisting of both chambers (anode and cathode) with an operational volume of $700 \mathrm{ml}$. Salt bridge (Solution of $1 \mathrm{M} \mathrm{KCl}$ and $2 \mathrm{~g}$ agar in $100 \mathrm{ml}$ distilled water) was prepared using polyvinyl chloride (PVC) pipe, which splits the two chambers (anode and cathode) to transfer protons from the anode chamber to the cathode chamber. Carbon rods ( $4 \times 5 \mathrm{~cm} ; 10 \mathrm{~mm}$ thickness) coated with non-conductive epoxy were used as electrodes for both anode and cathode (Table 1). Cassava mill effluent was used as a substrate, MFC set up generated a maximum voltage and current (275 $\mathrm{mV}$ and $2.75 \mathrm{~mA}$ ), resulting in the highest power density $\left(189 \mathrm{~mW} / \mathrm{m}^{2}\right)$. The data of this study proved that MFC technology could be used to produce bioelectricity directly from cassava mill effluent ${ }^{29}$.

\section{Dairy industrial wastes}

In a developing country like India, rapid urbanization has instigated severe urban migration among the rural populace for better employment which increased the demand for milk processing. 
The dairy industry wastewater is ambiguous as it contains sugars, proteins, and fats. About 2-2.5 liters of wastewater are generated for every liter of milk processed. As a result of this, a large amount of unused dairy wastewater is discharged which pollutes the atmosphere if not treated..$^{42}$ In one of the studies, MFC was developed without catalyst and mediator with two chambers divided by a proton exchange membrane, each containing twoelectrode made up of Nafion 117 membranes. A graphite plate is being used as common electrodes viz., anode, and cathode (Table 1). Industrial wastewater majorly dairy waste effluents is used as substrate and in a cathode chamber filled with phosphate buffer as electron receiver and catalyst. At a $1 \mathrm{k} \Omega$ external resistance, the highest power density and electric current intensity generated on the anode surfaces was $3.74 \mathrm{~mA}$ and $621.13 \mathrm{~mW} /$ $m^{2}$, respectively and the highest voltage generated was $0.856 \mathrm{~V} .^{43}$

\section{Domestic Wastewater}

MFCs technology can be used to generate electricity from domestic wastewater. The total outcome could be hampered by the high levels of COD in municipal or domestic wastes and the average COD levels in domestic wastewater are about $410 \mathrm{mg} / \mathrm{L}^{44}$ The MFCs developed with kitchen garbage as the substrate has also proved to be a good method to produce green electricity as well as to recycle the organic waste and to maintain a healthy and eco-friendly environment. ${ }^{45}$ A lab-scale two-chamber MFC was built using 1000 $\mathrm{ml}$ capacity plastic containers, and an operational volume of $800 \mathrm{ml}$. Graphite rods are used as electrodes with a higher surface area $\left(31.1 \mathrm{~cm}^{2}\right)$. The chambers are connected by a PVC coupled with a PEM for easy transfer of a proton from anode and cathode chambers by maintaining an anaerobic environment in the anode compartment (Table 1). The cathode chamber was kept open to air for maintaining aerobic conditions. MFC system was produced about $68 \mu \mathrm{A}$ of current and $889 \mathrm{mV}$ of voltage. ${ }^{46}$

\section{Commonly used microbes}

Microorganisms play a significant role in the operation of MFCs, i.e., they have a unique capacity to transmission the electrons from the outer membrane of the cell towards the anode and catalyze reduced electron acceptors by accepting electrons from the cathode surface. ${ }^{16}$ Microbes associated with MFC forms a thin layer of bacterial cell growth on the electrodes is called biofilm. ${ }^{3}$ The area of the biofilm formation determines the ability of microorganisms to produce the electrons and directly relates to decomposing the complex organic substrates in MFC. The bacterial species such as Shewanella, Propionibacterium freudenreichii, Lactococcus lactis, Geobacter, Cupriavidus basilensis, Pseudomonas $\mathrm{sp}$, Rhodoferax, etc. have been reported as electrogenic bacteria or exoelectrogens. ${ }^{47,8}$ These organisms are used as catalysts for generating electricity and decomposition of organic wastes or carbon-based biomass degradation (Table 1).

Pure cultures are also useful for determining the broad variety of processes that occur mediating the electrons, as well as the diverse actions of individual species in a mixed microbial culture. Klebsiella pneumonia, Desulfovibrio desulfuricans, Escherichia coli, and Saccharomyces cerevisiae are some of the pure cultures used in bioelectricity generation. ${ }^{25,16}$ Studies have demonstrated that pure microbial cultures have high electron transfer efficiency, due to low growth rates in a highly specific substrate, low energy transfer rates, and risk of unwanted contaminations limits its use, whereas mixed cultures are robust and more productive than pure strains. ${ }^{1}$ The symbiosis of microbes, compatibility in the use of substrates, and the reutilizing of electrons make mixed culture appropriate for bioelectricity production. A combination of cultures can acclimatize to a wide-ranging environmental condition and each species can perform a particular function that equally helps other species leading to better performance (Table 1).

Therefore, pure cultures and mixed are utilized in MFCs for the generation of electricity and domestic effluent treatment. ${ }^{48}$ The biofilms formed facilitate electron transfer directly from the outer membrane cytochromes (pili) act as a nanowire. Saccharomyces cerevisiae was used as electrogenic bacteria for the first time for power generation in MFC. ${ }^{3}$

Usually the life time of MFCs is directly depends on the microbial activity and nutrient resources or substrates available in the set up. As 
per the available data, the life time typical MFCs may works upto months to years but few reports are also depicts that, they showed very short life time of upto weeks also. ${ }^{49}$ The survivability of microbes in MFCs is major concern and especially in MFC most of the bacterial genera belongs anaerobic group. Maintenance of the anaerobic is difficult task for large scale application. ${ }^{50}$

\section{Future Perspective of MFCs}

Microbial fuel cell technology is a potential, emerging ecofriendly technology that meets the energy demand and resolve energy crisis in the future generation. The present electricity generation technologies is totally depend on the other natural energy resources and are depleting rapidly due to excess power utilization. Application and use of MFCs is approaching to the forefront as a multiple system for energy recovery and waste management simultaneously.

\section{CONCLUSION}

MFCs are encouraging technology towards generating electricity using organic waste and other domestic or industrial wastes. It acts as a green technology to generate electricity from biodegradable wastes with less emission and pollution. MFC technology could be used as an effective waste disposal method and it would assist in reducing environmental issues and human health arising from waste accumulation. For higher energy production, the optimization method includes the kind of microbial community used, substrates present in the medium, electrodes, is a key for enhancing energy output using MFC technology. Therefore, this method is ecosustainable and does not produce toxic substances. Hence, MFC technology has a huge potential to play an important role in solving the future energy crisis and effective waste management which distinguishes it from conventional energy sources.

\section{ACKNOWLEDGMENTS}

All the authors are thankful to Ramaiah University of Applied Sciences, Bangalore for providing seed money grants for the research work. All the authors are thankful to PRS editorial team (Publication Review Service) for technical support during the writing of this review article in an effective manner.

\section{CONFLICT OF INTEREST}

The authors declare that there is no conflict of interest.

\section{AUTHORS' CONTRIBUTION}

CG, NP, HKN drafted the manuscript and gathered information from the literature. NG, CK, $\mathrm{ACL}$ supervised and designed the figures and table.

\section{FUNDING}

None.

\section{DATA AVAILABILITY}

All datasets generated or analyzed during this study are included in the manuscript

\section{ETHICS STATEMENT}

Not applicable.

\section{REFERENCES}

1. Chaturvedi V, Verma P. Microbial fuel cell: a green approach for the utilization of waste for the generation of bioelectricity. Bioresources and Bioprocessing. 2016;3(1):38. doi: 10.1186/s40643-016-0116-6

2. Mekuto L, Olowolafe AV, Pandit S, Dyantyi N, Nomngongo P, Huberts R. Microalgae as a biocathode and feedstock in anode chamber for a self-sustainable microbial fuel cell technology: A review. South African J Chemical Eng. 2020;31:7-16. doi: 10.1016/j. sajce.2019.10.002

3. Franks AE, Nevin KP. Microbial fuel cells, a current review. Energies. 2010;3(5):899-919. doi: 10.3390/ en3050899

4. Li J. An experimental study of microbial fuel cells for electricity generating: performance characterization and capacity improvement. J Sustainable Bioenergy Systems. 2013;3(03):171-178. doi: 10.4236/ jsbs.2013.33024

5. Barua PK, Deka D. Electricity generation from biowaste based microbial fuel cells. Int J Energy Info Comm. 2010;1(1):77-92.

6. Zhao CE, Wu J, Ding Y, et al. Hybrid conducting biofilm with built-in bacteria for high-performance microbial fuel cells. Chem Electro Chem. 2015a;2(5):654-658. doi: 10.1002/celc. 201402458

7. Kumar R, Singh L, Wahid ZA, Din MFM. Exoelectrogens in microbial fuel cells toward bioelectricity generation: a review. Int J Energy Res. 2015;39(8):1048-1067. doi: 10.1002/er.3305

8. Fan X, Zhou Y, Jin X, Song RB, Li Z, Zhang Q. Carbon material-based anodes in the microbial fuel cells. Carbon Energy. 2021;3(3):449-472. doi: 10.1002/ cey2.113

9. Javalkar PD, Alam J. Comparative study on sustainable bioelectricity generation from microbial fuel cell using bio-waste as fuel. Int I Sci Res Publications. 
2013;3(8):1-6.

10. Ullah Z, Zeshan S. Effect of substrate type and concentration on the performance of a double chamber microbial fuel cell. Water Sci Technol. 2020;81(7):1336-1344. doi: 10.2166/wst.2019.387

11. Parkash A. Microbial fuel cells: a source of bioenergy. J Microbiol Biochem Technol. 2016;8(3):247-255. doi: 10.4172/1948-5948.1000293

12. Bose A, Bose D. Electricity Generation \& Other Applications using Microbial Fuel Cell. World Scientific News. 2016;39:17-30.

13. Prabu M, Durgadevi M, Tamilvendan M, Kalaichelvan PT, Kaviyarasan V. Electricity Production from Waste Water Using Microbial Fuel Cell. J Modern Biotechnol. 2012;1(1):19-25.

14. Al-Asheh S, Al-Assaf $Y$, Aidan A. Single-Chamber Microbial Fuel Cells' Behavior at Different Operational Scenarios. Energies. 2020;13(20):5458. doi: 10.3390/ en13205458

15. Slate AJ, Whitehead KA, Brownson DA, Banks CE. Microbial fuel cells: An overview of current technology. Renewable \& Sustainable Energy Reviews. 2019;101:60-81. doi: 10.1016/j.rser.2018.09.044

16. Kumar R, Singh L, Zularisam AW, Hai FI. Microbial fuel cell is emerging as a versatile technology: a review on its possible applications, challenges and strategies to improve the performances. Int J Energy Res. 2018;42(2):369-394. doi: 10.1002/er.3780

17. Rahimnejad M, Adhami A, Darvari S, Zirepour A, Oh SE. Microbial fuel cell as new technology for bioelectricity generation: a review. Alexandria Eng J. 2015;54(3):745756. doi: 10.1016/j.aej.2015.03.031

18. Pandey BK, Mishra V, Agrawal S. Production of bioelectricity during wastewater treatment using a single chamber microbial fuel cell. Int J Engineering Sci Technol. 2011;3(4):42-47. doi: 10.4314/ijest. v3i4.68540

19. Das S, Mangwani N. Recent developments in microbial fuel cells: a review. Journal of Scientific and Industrial Research. 2010;69(10):727-731.

20. Cheng $S$, Xing $D$, Logan BE. Electricity generation of single-chamber microbial fuel cells at low temperatures. Biosensors and Bioelectronics. 2011;26(5):1913-1917. doi: 10.1016/j.bios.2010.05.016

21. Sun J, Hu Y, Bi Z, Cao Y. Improved performance of air-cathode single-chamber microbial fuel cell for wastewater treatment using microfiltration membranes and multiple sludge inoculation. J Power Sources. 2009;187(2):471-479. doi: 10.1016/j. jpowsour.2008.11.022

22. Govind MA. Review on carbon electrodes in microbial fuel cell. Int Res J Eng Technol. 2015;2(8):424-427.

23. Ashoka H, Bhat P. Comparative studies on electrodes for the construction of microbial fuel cell. Int J Adv Biotech Res. 2012;3(4):785-789.

24. Zhao CE, Wu J, Kjelleberg S, Loo JSC, Zhang Q. Employing a flexible and low-cost polypyrrole nanotube membrane as an anode to enhance current generation in microbial fuel cells. Small. 2015;11(28):3440-3443. doi: 10.1002/smll.201403328

25. Wang VB, Du J, Chen X, et al. Improving charge collection in Escherichia coli-carbon electrode devices with conjugated oligoelectrolytes. Physical Chemistry Chemical Physics. 2013;15(16):5867-5872. doi: 10.1039/c3cp50437a

26. Mustakeem. Electrode materials for microbial fuel cells: nanomaterial approach. Materials for Renewable \& Sustainable Energy. 2015;4:22. doi: 10.1007/s40243015-0063-8

27. Cahyani FN. Tapioca waste water for electricity generation in microbial fuel cell (MFC) system. In 2nd International Conference on Environmental Science and Technology, IPCBEE volume. 2011;6:218-220.

28. Sivakumar D. Pollution reduction and electricity production from dairy industry wastewater with microbial fuel cell. Global J Environ Sci Management. 2020;6(2):145-164. doi: 10.22034/GJESM.2020.02.02

29. Agarry SE, Oghenejobor KM, Solomon BO. Bioelectricity production from cassava mill effluents using microbial fuel cell technology. Nigerian J Technol. 2016;35(2):329-336. doi: 10.4314/njt.v35i2.13

30. Liu Z, Liu J, Zhang S, Su Z. Study of operational performance and electrical response on mediator-less microbial fuel cells fed with carbon-and protein-rich substrates. Biochemical Eng J. 2009;45(3):185-191. doi: 10.1016/j.bej.2009.03.011

31. Feng $\mathrm{Y}$, Wang $\mathrm{X}$, Logan $\mathrm{BE}$, Lee $\mathrm{H}$. Brewery wastewater treatment using air-cathode microbial fuel cells. Appl Microbiol Biotechnol. 2008;78(5):873-880. doi: 10.1007/s00253-008-1360-2

32. Wen $Q, W u Y, C a o D$, Zhao L, Sun Q. Electricity generation and modeling of microbial fuel cell from continuous beer brewery wastewater. Bioresource Technol. 2009;100:4171-4175. doi: 10.1016/j. biortech.2009.02.058

33. Heilmann J, Logan BE. Production of electricity from proteins using a microbial fuel cell. Water Environ Res. 2006;78(5):531-537. doi: 10.2175/106143005X73046

34. Bolognesi S, Cecconet D, Capodaglio AG. Agroindustrial wastewater treatment in microbial fuel cells. Integrated Microbial Fuel Cells for Wastewater Treatment. Butterworth-Heinemann. 2020:93-133. doi: 10.1016/B978-0-12-817493-7.00005-9

35. ElMekawy A, Srikanth S, Bajracharya S, et al. Food and agricultural wastes as substrates for bioelectrochemical system (BES): the synchronized recovery of sustainable energy and waste treatment. Food Res Int. 2015;73:213-225. doi: 10.1016/j. foodres.2014.11.045

36. Garcia-Nunez JA, Ramirez-Contreras NE, Rodriguez DT, et al. Evolution of palm oil mills into biorefineries: Literature review on current and potential uses of residual biomass and effluents. Resources, Conservation \& Recycling. 2016;110:99-114. doi: 10.1016/j.resconrec.2016.03.022

37. Baranitharan E, Khan MR, Yousuf A, Teo WFA, Tan GYA, Cheng CK. Enhanced power generation using controlled inoculum from palm oil mill effluent fed microbial fuel cell. Fuel. 2015;143:72-79. doi: 10.1016/j.fuel.2014.11.030

38. Fan LP, Xu DD, Li C, Xue S. Molasses Wastewater Treatment by Microbial Fuel Cell with MnO 2-Modified Cathode. Polish J Environmental Studies. 2016;25(6): 2349-2356. doi: 10.15244/pjoes/64197 
39. Zhang YJ, Sun CY, Liu XY, Han W, Dong YX, Li YF. Electricity production from molasses wastewater in two-chamber microbial fuel cell. Water Sci Technol. 2013;68(2):494-498. doi: 10.2166/wst.2013.261

40. Wu CH, Liu SH, Chu HL, Li YC, Lin CW. Feasibility study of electricity generation and organics removal for a molasses wastewater by a waterfall-type microbial fuel cell. J Taiwan Institute of Chem Eng. 2017;78:150-156. doi: 10.1016/j.jtice.2017.05.019

41. Adekunle A, Raghavan V. Evaluation of the suitability and performance of cassava waste (peel) extracts in a microbial fuel cell for supplementary and sustainable energy production. Waste Manag Res. 2017;35(1):4755. doi: $10.1177 / 0734242 \times 16670487$

42. Elakkiya E, Matheswaran M. Comparison of anodic metabolisms in bioelectricity production during treatment of dairy wastewater in Microbial Fuel Cell. Bioresource Technol. 2013;136:407-412. doi: 10.1016/j.biortech.2013.02.113

43. Mansoorian HJ, Mahvi AH, Jafari AJ, Khanjani N. Evaluation of dairy industry wastewater treatment and simultaneous bioelectricity generation in a catalystless and mediator-less membrane microbial fuel cell. J Saudi Chemical Society. 2016;20(1):88-100. doi: 10.1016/j.jscs.2014.08.002

44. Munoz-Cupa C, Hu Y, Xu CC, Bassi A. An overview of microbial fuel cell usage in wastewater treatment, resource recovery and energy production. Sci of the Total Environ. 2020;754:142429. doi: 10.1016/j. scitotenv.2020.142429

45. Wlodarczyk PP, Wlodarczyk B. Wastewater treatment and electricity production in a microbial fuel cell with $\mathrm{Cu}-\mathrm{B}$ alloy as the cathode catalyst. Catalysts. 2019;9(7):572. doi: 10.3390/catal9070572

46. Manjrekar Y, Kakkar S, Durve-Gupta A. Bio-Electricity Generation Using Kitchen Waste and Molasses Powered MFC. IJSRSET. 2018;5(4):181-187.

47. Reiche A, Sivell JL, Kirkwood KM. Electricity generation by Propionibacterium freudenreichii in a mediatorless microbial fuel cell. Biotechnol Letters. 2016;38(1):5155. doi: 10.1007/s10529-015-1944-8

48. Kumar SS, Kumar V, Malyan SK, et al. Microbial fuel cells (MFCs) for bioelectric chemical treatment of different wastewater streams. Fuel. 2019;254:115526. doi: 10.1016/j.fuel.2019.05.109

49. Li WW, Yu HQ, He Z. Towards sustainable wastewater treatment by using microbial fuel cells-centered technologies. Energy \& Environmental Science. 2014;7(3):911-924. doi: 10.1039/C3EE43106A

50. Wang $\mathrm{P}$, Jia H. Power-generation from biorenewable resources: biocatalysis in biofuel cells. In Bioprocessing for value-added products from renewable resources. 2007;507-525). Elsevier. doi: 10.1016/B978044452114-9/50021-9 